\title{
PARAUMBILICAL HERNIA REPAIR DURING CAESAREAN SECTION; MATERNAL AND NEONATAL OUTCOMES
}

\author{
Wagih Ghnnam MD*, Adel Helal MD, Mohamad Fawzy MD, Ehsan Refaie MD, \\ Ahmed Ragab MD and Hend Shalaby MD. \\ *Department of General Surgery, Department of Obstetrics \& Gynecology, \\ Mansoura Faculty of Medicine, Mansoura University
}

\section{ABSTRACT}

Design \& Objectives : A prospective study to evaluate the outcome of combined caesarean section and paraumbilical hernia repair in tertiary referral university hospital.

Patients and methods: 48 patients undergoing caesarean section combined with paraumbilical hernia repair versus 100 patients undergoing caesarean section alone.

Main Outcome Measures: Operation time, Apgar Score, blood loss, uterine atony, breast feeding initiation, pain sensation, peripartum complications, prolonged lochia (more than 42 days), deep venous thrombosis, hospital stay, hernia recurrence, and patient choice.

Results: The combined procedure consumed significantly longer time than caesarean section alone in the mesh hernioplasty subgroup. There were no major complications. Apgar Score, uterine atony, initiation of breastfeeding, prolonged lochia, wound infection and hospital stay did not differ significantly from those of controls. Pain at hernia site repair in two patients, one hernia recurred in the primary repair subgroup during follow up the period up to 3 years. All hernia group patients reported that they preferred the combined operation.

Conclusion: Combined caesrean section and paraumbilical hernia repair had the advantage of single incision, single anesthesia, and single hospital stay. The combination approach proved to tbe safte, effective, and well accepted.

Key words : Umbilical hernia, mesh, suture repair, combined caesarean section-hernial repair.

\section{INTRODUCTION}

Umbilical hernia represents $6 \%$ of all abdominal wall hernias in adults ${ }^{(1)}$. There is no consensus on the best technique for the repair of umbilical hernia and various surgical techniques such as primary suture, Mayo repair, mesh repair, and laparoscopic surgery have been used for its treatment ${ }^{(2)}$.

Caesarean section(CS) has been practiced over centuries and had increased reaching a peak in the last three centuries ${ }^{(3)}$, CS has become such a safe procedure that women are requesting it to be used to deliver their baby in the absence of any other indication $^{(4)}$.

The combination of umbilical hernia repair with gynecologic surgery or caesarean section is virtually undocumented except as case reports ${ }^{(5)}$ and only few cases 8 patients) having inguinal and umbilical hernia repaired during $\mathrm{CS}{ }^{(6)}$. Combination of paraumbilical hernia repair with abdominal surgery remains little analyzed except in conjunction with cholecystectomy ${ }^{(7-8)}$.

Whether it is best to repair a hernia during the pregnancy itself, at caesarean section or post partum after involution of the uterus, remains a matter of dispute. Some authors recommended repair during pregnancy only in the case of strangulation and incarceration. Irreducible umbilical hernias have to be repaired before the enlarging uterus caused possible strangulation. Otherwise, if there were no complications during pregnancy, repair was to be deferred until as soon as possible post partum. One 
reason for deferral is that anesthesia and surgery during pregnancy could precipitate uterine irritability and induce premature labour, up to one weck postoperatively ${ }^{(9)}$.

Other proposed reasons have been the extreme vascularization of the uterus, and the induction of collagen remodeling by relaxin during pregnancy, with the softened tissue predisposing to hernia recurrence ${ }^{(10)}$.

\section{AIM OF THE STUDY}

It was aimed to study the effect of combined paraumbilical hernia repair and CS on the mothers and infants in the immediate post operative period Apgar Score, uterine atony, initiation of breast lecding, wound infection or disruption and the success and reccurrence rate. It was intended to compare outcome in this group with that of a comparable control group undergoing caesarean section alone.

\section{MATERIALS \& METHODS}

The study groups included 48 women with mean age $30.08 \pm 2.64$ years having paraumbilical hernia with pregnancy were scheduled for elective caesarean section. All 48 women underwent, with their informed consent, caesarean section combined with primary hernia repair under general anesthesia The studied cases were multiparous with non complicated pregnancies and all were selected to be non risky pregnant women. Cases with DM, HTN, liver or renal impairment, blood dyscrasias and endocrinopathies were not included. All were full term pregnancies.

All patients received antibiotic prophylaxis in the form of cefotaxim sodium $1 \mathrm{~g}$ intravenous with the induction of anesthesia. Skin disinfection with povidine iodine, Pfannensteil incision in the lower abdominal crease in all cases, lower segment CS, soon after delivery of the neonate, reduction of the inhaled ancsthesia concentration to $0.5 \%$ was undertaken also IV opioids (fentanyl) in small amount, intravenous oxytocin 10 IU over 10 minutes was given (cases who showed uterine atony received additional prostaglandin $\mathrm{El}$ analogue $400 \mathrm{mcg}$ transrectal), uterine closure in 2 laycrs and good haemostasis was done. We performed umbilical hernia repair by primary suture from inside when the defect is $<3$ centimeter $(\mathrm{cm})$ in 36 patients, or from inside mesh hernioplasty closing the defect when the defect is $>3 \mathrm{~cm}$ fixed to the peritoneum and sheath by non absorbable polyprolin suture in 12 patients.

Good peritoneal toilet and closure of the abdominal incision as usual. The severity of postoperative pain was evaluated by the averagc consumption of analgesic ampoules consumed by the patient during the first week. All patients received a routine intramuscular dose of $75-\mathrm{mg}$ of an analgesic (disclophenac sodium) twice on the day of the operation and the same dose was given as needed later on. Low molecular weight heparin (enoxaparin) $40 \mathrm{mg}$ once daily for the first 3 days of operation was given to all cases with stress upon good hydration and early mobilization.

Operative time, Apgar Score, uterine atony, initiation of breastfeeding, postoperative complications, and length of hospital stay were recorded. Wound infections, separations, seromas and hematomas were treated with local care and/or antibiotics, on an out-patient or in-patient basis. Prolonged lochia and the occurrence of deep venous thrombosis was stressed upon for reporting.

Wound infection was diagnosed if the wound drained purulent material or the incision required opening and showed two or more of the classical signs of infection, such as erythema, tenderness, induration, and fever. Wound seroma or hematoma was diagnosed in the presence of a scrous lluid collection or subcutancous blood without signs of 
infection. Wound disruption was defined as spontaneous or iatrogenic separation of the wound edges more than $1 \mathrm{~cm}$. Patients were followed-up daily till discharge from hospital, then every 3 days at outpatient for the first two weeks, then every month for six months and finally every 6 months for three years.

Descriptive statitistics in the form of mean \pm standard deviation, $t$ test, Mann-Whitney $U$, and Kruskal-Wallis tests were used as needed for statistical analyses.

\section{RESULTS}

A total of 148 patients were included in the study. As shown in Table I, their mean ages in the CS and hernia repair group (group I), and the CS alone (group II) were $30.08 \pm 2.64$ and $29.3 \pm 2.56$ years, respectively. Their mean BMI were $29.3 \pm 2.58$ and $28.51 \pm 2.41$ for group I and group II respectively and there were no significant differences with respect to age, BMI, parity nor gravidity.

Previous CS was the most common indication for cesarean section in both groups and other indications for CS are listed in Table II. Mean operative time was $78.2 \pm 19 \mathrm{~min}$. (range 55-120 min.). In group I, it was significantly, longer $(\mathrm{P}<0.001)$ in Group I when compared with that in Groups II $(60.5 \pm 10$ min.) The mean Apgar Score was (7.92 \pm 0.65$)$ in group $I$ and was $(8.0 \pm 0.77)$ in group II with no significant difference. The initial breastfeeding started 5-7 hours with mean of 5.79 \pm 0.65 for group $I$ and $5.63 \pm 0.49$ for group II with no statistical difference (Table III). Mean length of hospital stay was $3.6 \pm 0.86$ days (range 3-6 days) in group I, while it was $3.4 \pm 1.2$ days (range 3-9 days) n group II with no significant difference between the two groups $(P=0.24)$. No significant difference was noticed as regard pre and postoperative mean hemoglobin level in both groups (Table II).

The patients in the combined CS and hernia repair group described more pain, The need for analgesics was significantly less in the CS alone group in comparison to group $I(P=0.008)$.

The rate of early and late postoperative complications such as seroma and/or hematoma, wound infection, and wound disruption was similar among both groups (Table III). Prolonged lochia (more than 42 days) was noticed in two cases of group.II and in one case of group I with no statistical differences. There was one recurrence $(2.8 \%)$ in the suture repair subgroup, whereas no recurrence was detected in the mesh hernioplasty subgroup. Deep venous thrombosis was not encountered in any case.

The mean follow-up time was 22 months. Caesarean section suture healing was delayed, with wound infection, in 6 patients $(2$ in the combined CS $\&$ hernia repair group and 4 in the CS alone group). (Table III). The patients expressed subjective satisfaction to the combined procedure.

No postoperative mortality was observed. Recurrence rate in patients of suture-receiving subgroup was statistically significant when compared with patients of mesh-receiving group $(\mathrm{P}<$ 0.03 ).

\section{DISCUSSION}

The failure to combine hernia repair with cesarean section remains unexplained and most obstetricians believe that they do not need to add more risk to their patients from combined surgery with CS because no hurry to repair paraumbilical hernia. The effect of prolonged anesthesia and its type also the effect of Caesarean section and its surgical time on the initiation of breastfeeding and postpartum haemorrage still are points of controversy $(11-16)$.

Umbilical hernias are prone to incarceration and continue to enlarge if untreated, and thus they should be considered for repair at presentation (17). The combination of umbilical hernia repair with $\mathrm{CS}$ is 
sactually undocumented except as case report with only few cases ${ }^{(6)}$.

Proponents of postpartum hernia repair may be argued that the combined procedure increases the complication ràte, blood loss and wound infection resulting from the longer operation time and prologned hospitalization.

Our data confound this view. Hernia repair prolonged the average duration of cesarean section, but the time remained within the normal range reported for hernia repair in the literature. In all patients undergoing paraumbilical hernia repair operation times remained below 120 minutes.

In our study, wound infection rate in the combined CS and hernial repair was $4.2 \%$ a little bit lower than that reported by many investigators

Table (I): Age, pariicy and gravidity in the studied groups.

\begin{tabular}{|l|c|c|c|c|}
\hline & $\begin{array}{c}\text { Group I combined } \\
\text { Hernia \& CS } \\
(\mathbf{n = 4 8})\end{array}$ & $\begin{array}{c}\text { Group II CS alone } \\
(\mathbf{n = 1 0 0 )}\end{array}$ & F. ratio & $\begin{array}{c}\text { P } \\
\text { vaine }\end{array}$ \\
\hline BMI (mean \pm SD) & $29.3 \pm 2.58$ & $28.51 \pm 2.41$ & 3.17 & 0.07 \\
\hline Age (mean \pm SD) & $30.08 \pm 2.64$ & $29.3 \pm 2.56$ & 2.99 & 0.08 \\
\hline Parity (mean \pm SD) & $2.14 \pm 1.07$ & $1.5 \pm 1.01$ & 1.125 & 0.61 \\
\hline Gravidity (mean \pm SD) & $3.39 \pm 1.1$ & $2.66 \pm 1.02$ & 1.159 & 0.53 \\
\hline
\end{tabular}

Table (II): Indications of CS, operative time, hospitalization time and pre \& post operative mean haemoglobin level in the studied groups.

\begin{tabular}{|c|c|c|c|}
\hline Parameter & $\begin{array}{c}\text { Group I combined } \\
\text { Hernia \& CS } \\
(n=48)\end{array}$ & $\begin{array}{l}\text { Group II CS alone } \\
\quad(\mathrm{n}=\mathbf{1 0 0})\end{array}$ & $\begin{array}{c}P \\
\text { value }\end{array}$ \\
\hline $\begin{array}{l}\text { Indications for CS: } \\
\text { * Primary CS } \\
\text { - CPD } \\
\text { - Failure to progress } \\
\text { - Malpresentation } \\
\text { - PROM } \\
\text { * Repeat CS }\end{array}$ & $\begin{array}{c}\text { Patients (\%) } \\
1 \\
(2.8) \\
9 \\
(18.75) \\
4 \quad(8.3) \\
3 \\
(6.25 \\
\\
31 \\
(64.6)\end{array}$ & $\begin{array}{c}2 \\
(2) \\
18 \\
(18) \\
9 \quad(9) \\
7 \\
(7) \\
\\
64 \\
(64)\end{array}$ & Not sign. \\
\hline Operative time (mean \pm SD) & $78.2 \pm 19(55-120)$ & $60.4 \pm 10(45-90)$ & \\
\hline Hospital stay (mean $\pm \mathrm{SD}$ ) & $306 \pm 0.86$ & $3.4 \pm 1.2$ & \\
\hline Preoperative haemoglobin (mean $\pm \mathrm{SD}$ ) & $12.5 \pm 5.7$ & $13.4 \pm 6.2$ & \\
\hline Postoperative haemoglobin (mean $\pm \mathrm{SD}$ ) & $11.4 \pm 4.5$ & $12.2 \pm 5.3$ & \\
\hline
\end{tabular}

Not sig. $=$ not significant, $\mathrm{CPD}=$ cephalopelvic disproportion, $\mathrm{PROM}=$ premature rupture of membranc. 
Table (III): Apgar Score, Initiation of breastfeeding, uterine atony, use of postoperative analgesic and complications in the studied groups:

\begin{tabular}{|l|c|c|c|}
\hline \multicolumn{1}{|c|}{ Parameter } & $\begin{array}{c}\text { Group I combined } \\
\text { Hernia \& CS } \\
(\mathbf{n = 4 8 )}\end{array}$ & $\begin{array}{c}\text { Group II CS alone } \\
(\mathbf{n = 1 0 0 )}\end{array}$ & $\begin{array}{c}\text { P } \\
\text { value }\end{array}$ \\
\hline Apgar Score (5 min) & $7-9(7.91)$ & $6-9(8.0)$ & 0.51 \\
\hline Initiation of breastfeeding (mean) & $5-7$ hours $(5.79)$ & $5-6$ hours (5.63) & 0.93 \\
\hline Uterine atony & $1(2.08 \%)$ & $1(1 \%)$ & 0.59 \\
\hline Mean analgesic ampoules used & $4.97 \pm 1.2$ & $4.45 \pm 0.86$ & 0.008 \\
\hline Wound sepsis & $2(4.17 \%)$ & $4(4 \%)$ & 1.000 \\
\hline Seroma & $1(2.08 \%)$ & $2(2 \%)$ & 1.000 \\
\hline Wound disruption & $0(0 \%)$ & $1(1 \%)$ & 1.000 \\
\hline Prolonged lochia & $1(2.08 \%)$ & $2(2 \%)$ & 1.000 \\
\hline DVT & 0 & 0 & \\
\hline
\end{tabular}

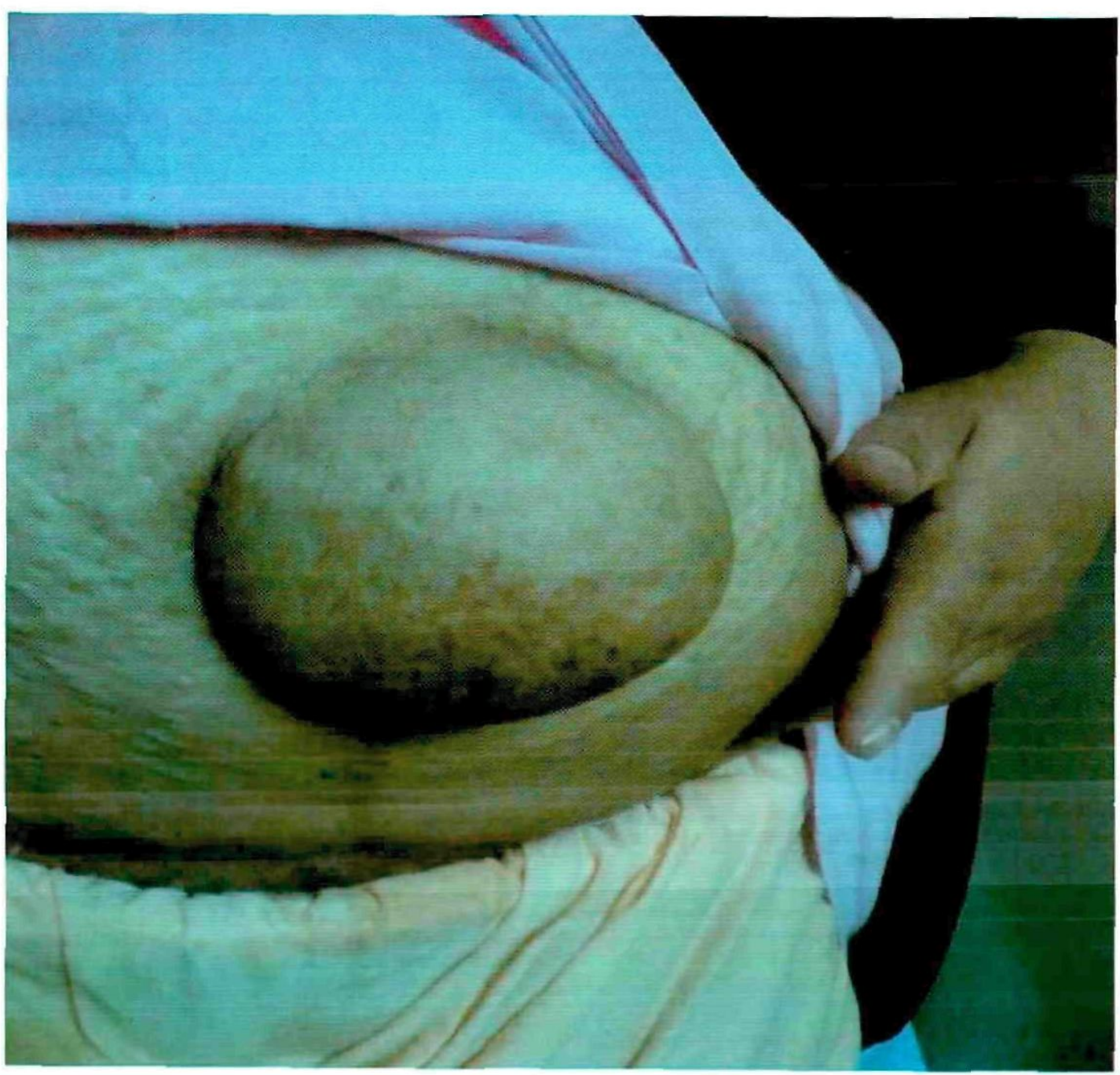

Fig. 1.:Paraumbilical hernia during pregnancy 


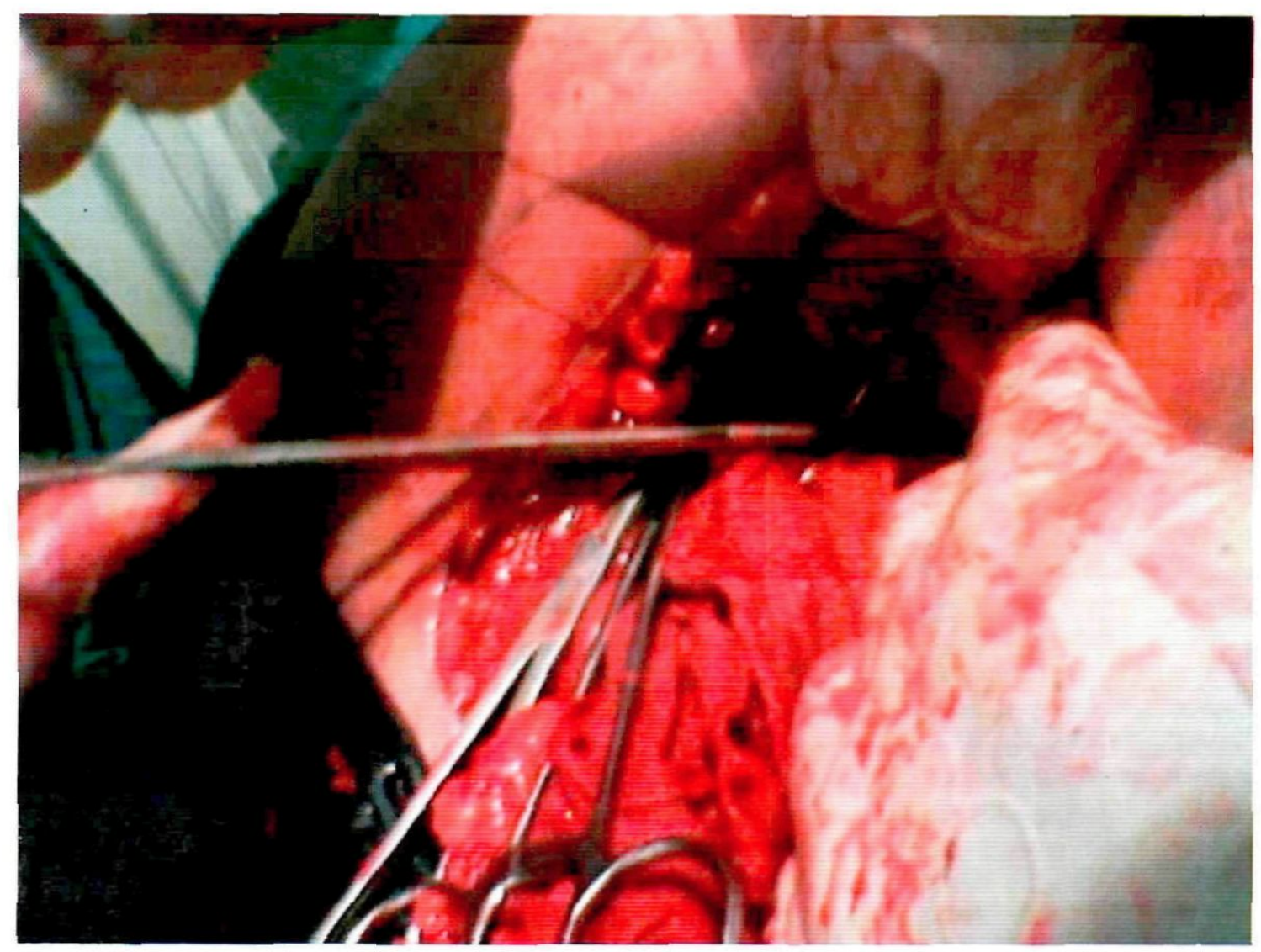

Fig. 2.: Intraoperative view showing difficulty of mesh fixation.

(18-20) while it was $4 \%$ in CS alone group with no signifficant difference.

Hospitalization was not prolonged in patients undergoing the combined procedure; total number of seroma formation occurred in 3 patients $(2 \%)$ and wound disruption in one patient $(0.68 \%)$ (Table III).

Uterine atony rarely occurred in our studied cases; it happened in only one case of group I and one case of group II with no statistical difference. This is against many investigators. Fassolt et al, 1976 (21); stressed upon the effect of narcotics on uterinetone. Tessier, et al $2004^{(13)}$; put CS as one of the identifiable risk factors for postpartum hemorrhage while analgesia and anesthesia are uncertain risk factors.

In the present series no major postpartum hemorrhage occurred inspite of CS and prolonged anesthesia especially in hernia repair group. This may be due to the active management of he third stage of labour by giving IV oxytocin $10 \mathrm{IU}$ immediately after delivery of the fetus. This is in accordance to Kikutani et al, $2006^{(22)}$ who found that IV oxytocin is more beneficial than IV ergometrine in managing the third stage of labour.

Inspite of the prolonged operation times in cases with combined repair and CS also inspite of the type of anesthesia (general) in all our cases the initiation of breastfeeding was within a reasonable time $(5.7 \pm$ $0.65 \mathrm{hs}$ ) for $\mathrm{CS}$ alone and $5.63 \pm 0.49 \mathrm{hrs}$ in the combined surgical group with insignificant differences.

As regards breastfeeding, our results are against many investigators who had studied the effect of CS, the type and duration of anesthesia and surgery itself on the initiation of breastfeeding, Pere $z$ et al, 2008 (23); Chen et al, $2008^{(15)}$ found that CS per se was negatively related to breastfeeding initiation. Negative effect of general anesthesia on breastfeeding was shown by many investigators (12,24-26). While, Mathur et al, 1993 (11) suggested that CS under spinal anesthesia promotes early initiation of breastfeeding. 
The rapid initiation of breastfeeding in our cases (Table III) may be due to the authors, promotion to the mothers for early initiation of breastfeeding and/or may be due to the effect of opioids in small amounts given to the mothers immediately after delivery of their babies.

Goma et al, $2008^{(16)}$ concluded that fentanyl intravenous or epidural can be safely used in CS without affecting the initial breastfeeding behaviors of the newborn, while Wang et al, 2005 (14) concluded that continuous epidural anesthesia and post partum analgesia are effective with little side effects and that the analgesic effect reduces catecholamine, promotes prolactin secretion and benefits breastfeeding.

No cases developed DVT inspite of prolonged surgery and prolonged general anesthesia (Table III), this is against many investigators (27-28). The absence of DVT in our study may be due to our application of RCOG, $2003{ }^{(29)}$ recommendation of early mobilization, good hydration and the use of low moleculer weight heparin for three days following surgery.

The recurrence rate was $2.8 \%$ for suture repair group and no recurrence in mesh group. Despite the high frequency of the umbilical hernia repair procedure, disappointingly high recurrence rates, up to $54 \%$ for simple suture repair ${ }^{(30)}$. Large differences in hernia recurrence rates have been reported: between $10 \%$ to $30 \%$. depending on sugical technique, length of follow-up, and method of recurrence assessment. Rates also increase with time, with most recurrences occurring early, in the first 3 months after mesh repair ${ }^{(30-32)}$.

\section{CONCLUSION}

The potential benclits of combining cesarean section with hernia repair are evident, with no increase in complications, notably infection, in comparison to cesarean section alone. Furthermore, all patients continued to indicate the acceptability of the combined procedure.

The practical benefits are obvious: a two-in one operation, with a single incision, single anesthesia, and single hospital stay, conferring valuable advantages for both patient and hospital in time, cost, and convenience, not to mention avoiding the separation of mother from newborn entailed by reoperation.

Cesarean section combined with paraumbilical hernia repair appears safe, effective, avoids rehospitalization and is well accepted. It neither increased the complication rate nor prolong the hospital stay and is associated with acceptable recurrence rate.

Confirmation of these results in a larger study including also other types of ventral hernia would establish combined cesarean section and hernia repair as a recommendable procedure.

Acknowledgement: we thank all our patients for their contribution and assistance Details of ethics approval and Funding: this research is approved by our university (Mansoura Faculty of Medicine research committee) no external funds were used.

\section{REFERENCES}

1. Perrakis E, Velimezis G, Vezakis A, Antoniades J, Savanis G. and Patrikakos V.: A new tension-free technique for the repair of umbilical hernia, using the Prolene Hernia System-ealry result from 48 cases. Hernia 2003; 7 : 178-180.

2. Wright BE, Beckerman J, Cohen M, Cumming JK and Rodriguez JL.: Is laparoscopic umbilical hernia repair with mesh a reasonable alternative to conventional repair? AM J Surg 2002; 184: 505-509.

3. Hassan A. Trial of scar and vaginal birth after cesarean section. J Ayub Med Coll Abbottabad 2005; 17(1): 57-61.

4. Simm A, - and Ramoutar P: Caesarean section: techniques and complications. Current Obstetrics \& Gynaecology 2005; 15, 80-86.

5. Altchck A, rudick J. Preperitoneal herniorrhaphy: adjunct to cesarcan section. Obstet Gynecol. 1987; $70 ; 3: 470-471$.

6. Ochsenbein N., Demartine N., Ochsenbein-Imhof N. and zimmormann R. Cesarean section and simultaneous hernia repair. Arch Surg. 2004; 139: 893-895.

7. Lanzafame RJ. Techniques for the simultaneous management of incarcerated ventral herniae and 
cholelithiasis via laparoscopy. J Laparoendose Sugr. 1993; 3; 193-201.

8. Ikard.RW. Combining laparoscopic cholecystectomy and (peri) umbilical herniorrhaphy. Am Surg. 1995 $61: 304-305$

9. Kort B, Katz VL and Watson WJ. The effect of nonobstetric operation during pregnancy. Surg Gynecol Obstet. 1993; 177: 371-376.

10. Bani D. : Relaxin: a pleiotropic hormone. Gen Pharmacol. 1997; 28: 13-22.

11. Mathur GP, Pandy PK, Mathur S, Sharma S, Agnihorti M, Bhalla M, Bhalla JN: mBreastfeeding in babies delivered by cesarean section. Indian Pediatr. 193; 30 (11): 1285-1290.

12. Albani A, Addamo P, Renghi A, Voltolin G, Peano L, Ivani G.: (The effect on breastfeeding rate of regional anesthesia technique for cesarean and vaginal childbirth). Minerva Anestesiol. 1999; 65(9); 625-630.

13. Tessier V, Pierre F; College National des Gynecologues et Obstetriciens Francais; Agence Nationale d'Accreditation et d'Evaluation en Sante. (Risk factors of postpartum hemorrhage during labour and clinical and pharmacological prevention). J Gynecol Obstet Biol Reprod (Paris). 2004; 33 (8 suppl): 4S29-4S56.

14. Wang BP, Li QL, Hu YF.: (Impact of epidural anesthesia during delivery on breast feeding) $\mathrm{Di} Y \mathrm{Y}$ Jun Yi Da Xue Xue Bao. 2005; 25 (1): 114-5, 118.

15. Chen LH, Liu CK, Merett C, Chuo YH, Wan KS: Initiation of breastfeeding lessons from Taiwan. Paediatr Nurs. 2008; 20(3): 34-36.

16. Goma HM, Said RN, El-Ela AM: Study of the newborn feeding behaviors and fentanyl concentration in colostrum after an analgesic dose of epidural and intravenous fentanyl in cesarean section. Saudia Med J. 2008; 29(5): 678-682.

17. Rodriguc\%. A., and Hinder R., Surgical Management of Umbilical Hernia. Operative Techniques in General Surgery 2004, 6, 3,: 156-164.

18. Simchen E, Wax $\mathrm{Y}$, Galai $\mathrm{N}$ and Israeli $\mathrm{A}$. Differential effect of risk factors on early and late wound infections in patients undergoing herniorrhaphies. Ann Epidemiol. 1992; 2: 263-272.

19. Dodson MK, Magann EF and Meeks GR. A randomized comparison of secondar closure and secondar intention in patients with superficial wound dehiscence. Obstet Gynecol 1992; 80: 321.

20. Naumann RW, Hauth JC, Owen J, Hodgkins PM and Lincoln T. Subcutaneous tissue approximation in relation to wound disruption alter cesarean delivery in obese women. Obstet Gynecol 1995: 85: 412

21. Fassolt A, Schubiger V, Hauser OA.: (The uterotropismus of halothane, chlorofiom or methoxyflurane in clinical use-author's trans| Geburtshilfe Frauenheilkd. 1976; 36 (11): 919-427.

22. Kikutani T, Kikutani M, Oshima M, Sugmoto K, Shimada Y.: (Effects of methylergometrine and oxytocin on blod loss and uterine contraction during cesarean section). Masui. 2006; 55(5): 590-594.

23. Perez-Rios, Ramos-Valencia G, Ortiz AP: Ccsarcan delivery as barrier for breastfeeding inituation: the puerto Rican experience. J Hum Lact. 2008; 24(3): 293-302. Epub 2008 Jun.

24. Sener EB, Guldogus F, Karakaya D, Baris S, Kocamanoglu S, Tur A.: Comparison of neonatal effects of epidural and general anesthesia for cesarean section. Gynecol Obstet Invest. 2003; 55(l): 41-45.

25. Awi DD, Alikor EA.: Barriers to timely initiation of breastfeeding among mothers of healthy fulltcrm babies who deliver at University of Port Harcout Teaching Hospital. Niger J Clin Pract. 2006; 9(1): $57-64$.

26. Cakmak H, Kuguoglu S.: Comparison of the breastfeeding patterns of who delivered their hahics per vagina and via cesarean section : an observational study using the LATCH breastfeeding chartung system. Int J Nurs Stud. 2007; 44(7): 1128-11.37.

27. Sotunmbi PT, Idowu AT, Akang EE, Aken'Ova YA: Prevalence of venous thromboembolism at post-mortem in an African population: a cause of concern. Afr J Med Sci. 2006; 35(3): 345-348.

28. Jacobsen AF, Skjeldestad FE, Sandset PM: Ante-and postnatal risk factors of venous thrombosis: a hospital-based case-control study. J Thromb Haemost. 2008; 6(6): 905-912.

29. Royal Collage of Obstetricians and Gynaccologısts: Guideline No XX.: Thromboprophylaxis During Pregnancy and after Normal Vaginal Delivery. 2003.

30. Halm J., Heisterkam J., Veen $H$. and Weidema W.: Long-term follow-up after umbilical hernia repair: are there risk factors for recurrence after simple and mesh repair Hernia 2005; 9: 4: 334-337.

31. Arroyo A, Garcia P, Perez F, Andreu J, Candela I: and Calpena R. Randomized clinical trial comparing suture and mesh repair of umbilical hernia in adults. Br J Surg. 2001; 88: 1321-1323.

32. Muschaweck U. Umbilical and epigastric hernia repair. Surg Clin Norht Am 2003; 83: 1207-1221. 